\title{
The Effect of Rounding in Bump Foil Structure on the Dynamic Performance of Foil Journal Bearings
}

\author{
Hongyang Hu and Ming Feng* \\ School of Mechanical Engineering, University of Science and Technology Beijing, \\ 30 Xueyuan Road, Haidian District, Beijing 100083, China \\ *Corresponding author: Ming Feng (mingfeng@me.ustb.edu.cn)
}

Manuscript received 03 June 2019; accepted 14 August 2019; published 15 December 2019

Presented at the International Tribology Conference Sendai 2019, 17-21 September, 2019

\begin{abstract}
The performance of air foil journal bearings is closely related to the stiffness of the bump foil. In this paper, the stiffness characteristics of bump foil having a rounding in the structure are investigated and compared with previous models. The dynamic coefficients of bearings and the stability threshold speed (STS) of a rotor supported by the bearings are numerically calculated using FEM and are compared to models with various rounding radius and friction coefficients. The results show that the presence of rounding indicates a significant effect on the total dynamic and the stability performance of foil bearings and there is an optimum rounding radius to maximize the structural stiffness and stability. The validity of the theoretical analysis was verified by the structural stiffness and stability experiments. The results are expected to be helpful to bearing designers, researchers, and academicians concerned.
\end{abstract}

\section{Keywords}

foil journal bearing, rounding radius, dynamic coefficients, stability threshold speed (STS)

\section{Introduction}

Bump foil bearings are self-acting bearings that enable the damping capability from compliant structures, which is used successfully on many oil-free turbines. During bump foil strip manufacturing, the rounding of the bump foil is formed as a small circle between the bridge and the bump foil, which may change bending moments, stiffness of bump and the performance of bearings due to vertical and horizontal forces. The elastic model for the bump foil structure was first proposed by Walowit and Heshmat [1-3]. Carpino and Talmage [4] have developed a finite element model that models structural damping as viscous damping, which clearly explained the effect of Coulomb friction on foil bearing performance. Lez SL et al. [5] used finite element commercial codes to perform more accurate numerical analysis and investigated the static and dynamic characteristics of the foil structure. Feng and Kaneko [6] considered the bump foil as two rigid links and one horizontally spaced spring. In a model, the deflection of bump was analyzed by applying three boundary conditions such as pivot-pivot, pivot-fixed, and fixed-fixed [7]. Recently, a model considering the bending moment at each bump has been studied [8]. Swanson [9] developed a simplified model of foil in existing bump models using load-dependent friction elements.
Peng and Carpino [10] modeled the bump foil structure as a spring and damper and evaluated the interactions between bumps neglecting the friction between the top foil and the bump foil. A study on the rounding between foil and bridge was first proposed by Lehn A et al. [11]. They modeled a twodimensional shell of thickness to provide a fully coupled elastic gas kinetic model for air foil thrust bearings. However, the effect of the rounding on the performance of the bearing is not studied. San Andres [12] analyzed gas foil bearings integrating finite element top foil model to predict the hydrodynamic performance of foil journal bearings. FangCheng Xu [13] discussed the role of shear stiffness in the top foil structure based on the thick plate theory.

In this paper, the foil is modeled by the strain energy theory and moment equations. The dynamic coefficients and the dimensionless stability threshold speed (STS) of gas foil bearing are got by the perturbation method. Change of stiffness, damping coefficients, and the STS of foil bearing are discussed to study the effect of rounding on the performance.

\section{Theoretical analysis and experiment design}

2.1 The considered bump foil stiffness model

The structure of the first generation bump foil bearing is 
a

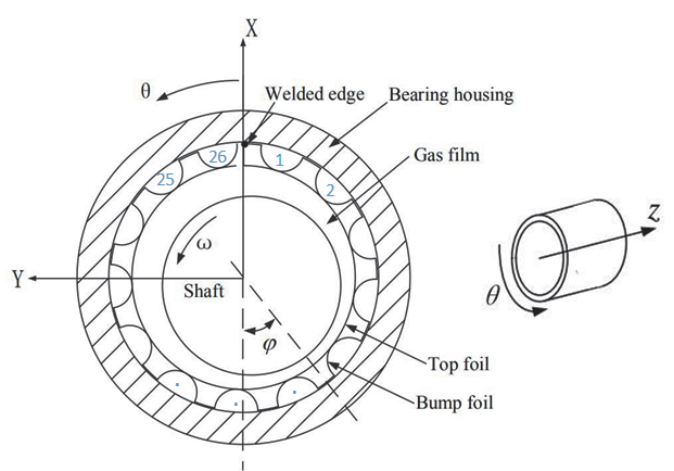

b

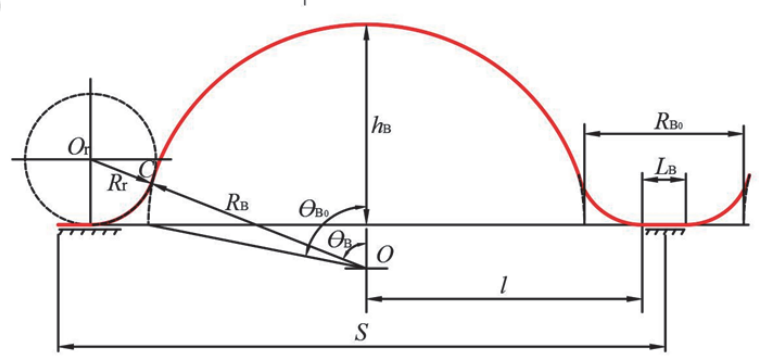

Fig. 1 Structure sketch: (a) bump foil bearing, (b) single bump with rounding

shown in Fig. 1(a), which consists of a top foil and a series of bump foil strip. Due to the manufacture of the foil bearing, there is always a rounding between the bump and bridge, which is always neglected but important in bump stiffness model. Figure 1(b) shows the model of a bump foil structure with rounding, in which $C$ is the contact point between the rounding and bump. The bump radius $R_{B}$, the bump height angle $\theta_{B 0}$, and the length of the bridge $L_{B O}$ represent the geometry of the previous bump model. The bump foil model with the rounding radius $R_{r}$ is as follows [11].

$$
\cos \theta_{\mathrm{B}}=\frac{R_{\mathrm{B}} \cdot \cos \theta_{\mathrm{BO}}+R_{r}}{R_{\mathrm{B}}+R_{r}}
$$

The effective half-length of the bump and the effective length of the bridge can be expressed as

$$
\begin{aligned}
& l=\left(R_{B}+R_{r}\right) \sin \theta_{B} \\
& L_{B}=L_{B 0}-2 \cdot\left[\left(R_{B}+R_{r}\right) \sin \theta_{B}-R_{B} \sin \theta_{B 0}\right]
\end{aligned}
$$

As the bump height $h_{B}$ can be calculated by other parameters, the geometric structure is completely determined by $R_{B}, \theta_{B 0}, L_{B 0}$ and $R_{r}$. When $R_{r} \rightarrow 0$, the bump strip is represented by a special foil model. The structural deformation of bump foil strip under an arbitrary pressure is shown in Fig. 2(a). The force $W_{i}$ acting on each bump is the same as the previous models [14]. The right end is free to move in the $x$-direction (horizontal) and the $y$-direction (vertical). Local deflection in the $y$ direction under load is $\delta_{W i}$. The foil strip will slide to the free end depending on the friction coefficient between the bump and housing $\mu$, as well as that between the bump and top foil $\eta$. The main assumption for the present analysis is as follows:

(1) Top foil follows the deflection of the bump foil, but does not significantly affect bump deformation.

(2) Bridge between two bumps does not deflect and separate from the housing surface.

(3) All deformations of foil strips are elastic, and no permanent deformation occurs. a

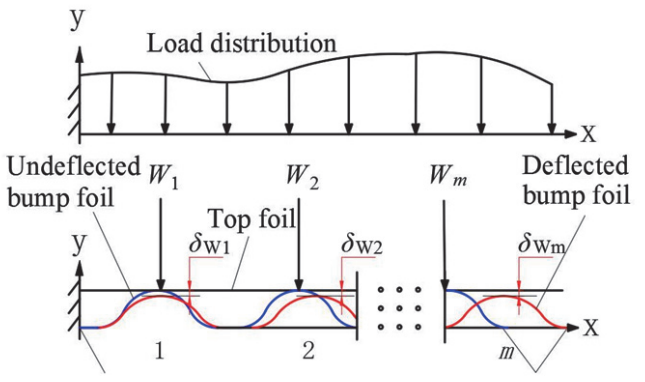

b

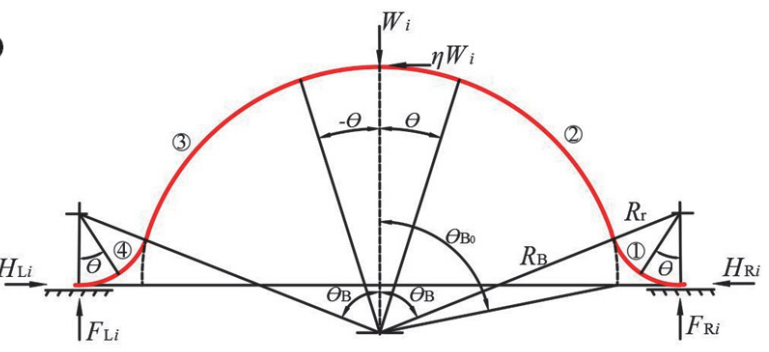

Fig. 2 Analysis of bump foils: (a) deflection of bump foil strip, (b) force of single bump

(4) Tangent point $B$ between the rounding $R_{r}$ and the foil strip $R_{B}$ is placed on a straight line of the two centers.

(5) When the rounding is bent, the contact effect between rounding and housing is neglected.

The bump foil is divided into four sections in Fig. 2(b): two main foil sections of bump strip $\left(0 \leq \theta \leq \theta_{B},-\theta_{B} \leq \theta \leq 0\right)$ and the other two rounding sections $\left(0 \leq \theta \leq \theta_{B}\right)$. The horizontal force and the vertical force acting on the right end of the ith bump and static equilibrium of two reactions can be obtained by

$$
P_{R i}=H_{R i}-\mu F_{R i}
$$

Where, $P_{R i}$ is the force transmitted through the bridge from the left end of the $i+1$ th bump. Meanwhile, on the right side of the $i$ th bump, there is a resisting force $T_{R i}$.

$$
T_{R i}=\sum_{n=i+1}^{n=N}(\mu+\eta) W_{n}
$$

The state of the $i$ th bump is determined by the comparison of $P_{R i}$ and $T_{R i}$ [15]. The bending moment at an arbitrary angle $(\theta)$ on each section of the $i$ th bump can be written as

$$
\begin{aligned}
M_{1 i}(\theta)= & -F_{R i} R_{r} \sin \theta+H_{R i} R_{r}(1-\cos \theta) \quad 0<\theta \leq \theta_{B} \\
M_{2 i}(\theta)= & -F_{R i}\left[\left(R_{B}+R_{r}\right) \sin \theta_{B}-R_{B} \sin \theta\right] \\
& +H_{R i}\left[R_{r}+R_{B} \cos \theta-\left(R_{B}+R_{r}\right) \cos \theta_{B}\right]
\end{aligned}
$$

$0<\theta \leq \theta_{B}$

$$
\begin{aligned}
M_{3 i}(\theta)= & -F_{R i}\left[\left(R_{B}+R_{r}\right) \sin \theta_{B}-R_{B} \sin \theta\right] \\
& +H_{R i}\left[R_{r}+R_{B} \cos \theta-\left(R_{B}+R_{r}\right) \cos \theta_{B}\right] \\
& -W_{i} R_{B} \sin \theta-\eta W_{i} R_{B}(1-\cos \theta)
\end{aligned}
$$

$-\theta_{B} \leq \theta \leq 0$

$$
\begin{aligned}
& M_{4 i}(\theta)=-F_{\mathrm{Ri}}\left[2\left(R_{B}+R_{r}\right) \sin \theta_{B}-R_{r} \sin \theta\right]+H_{R i} R_{r}(1-\cos \theta) \\
& \quad+W_{i}\left[\begin{array}{l}
\left.\left(R_{B}+R_{r}\right) \sin \theta_{B}\right]-\eta W_{i}\left[R_{B}+R_{r} \cos \theta_{B}-\left(R_{B}+R_{r}\right) \cos \theta_{B}\right] \\
-R_{r} \sin \theta
\end{array}\right] \\
& 0<\theta \leq \theta_{B}
\end{aligned}
$$


Where, $\theta_{B}$ is the included angle between the top center and point $B$ of the $i$ th bump foil.

When the ratio of bump $\left(R_{B} / t\right)$ is greater than 10 , the resulting error is often less than $1 \%$ and will seldom exceed $5 \%$. Since the bump thickness $t$ is very small compared to the bump radius $R_{B}$, the normal and shear forces can be neglected in the bearing analysis. Therefore, only the elastic deformation energy in the present analysis can be considered. Castigliano's second theorem is used to calculate the elastic deflection $\delta_{i}$ from $H_{R i}$ and $F_{R i}$.

$$
\begin{aligned}
\delta_{H i}= & \frac{\partial U}{\partial H_{R i}}=\int_{0}^{\theta_{\mathrm{B}}} \frac{M_{1 i}}{D L} \cdot \frac{\partial M_{1 i}}{\partial H_{R i}} R_{r} d \theta+\int_{0}^{\theta_{B}} \frac{M_{2 i}}{D L} \cdot \frac{\partial M_{2 i}}{\partial H_{R i}} R_{B} d \theta \\
& +\int_{-\theta_{\mathrm{B}}}^{0} \frac{M_{3 i}}{D L} \cdot \frac{\partial M_{3 i}}{\partial H_{R i}} R_{B} d \theta+\int_{0}^{\theta_{B}} \frac{M_{4 i}}{D L} \cdot \frac{\partial M_{4 i}}{\partial H_{R i}} R_{r} d \theta \\
\delta_{V i}= & \frac{\partial U}{\partial F_{R i}}=\int_{0}^{\theta_{B}} \frac{M_{1 i}}{D L} \cdot \frac{\partial M_{1 i}}{\partial F_{R i}} R_{r} d \theta+\int_{0}^{\theta_{B}} \frac{M_{2 i}}{D L} \cdot \frac{\partial M_{2 i}}{\partial F_{R i}} R_{B} d \theta \\
& +\int_{-\theta_{B}}^{0} \frac{M_{3 i}}{D L} \cdot \frac{\partial M_{3 i}}{\partial F_{R i}} R_{B} d \theta+\int_{0}^{\theta_{B}} \frac{M_{4 i}}{D L} \cdot \frac{\partial M_{4 i}}{\partial F_{R i}} R_{r} d \theta
\end{aligned}
$$

The flexural rigidity of the $i$ th bump foil is defined by

$$
D=\frac{E t^{3}}{12\left(1-v^{2}\right)}
$$

Where, $E, t$, and $v$ are Young's modulus, thickness and Poisson ratio of bump foil, respectively. If the right end of the $i$ th bump is assumed to be pinned-down, then the following matrix equation can be deduced from the boundary conditions $\left(\delta_{H i}=0, \delta_{V i}=0\right)$.

$$
\left[\begin{array}{cc}
D_{1} & D_{2} \\
D_{4} & D_{5}
\end{array}\right]\left\{\begin{array}{l}
F_{R i} \\
H_{R i}
\end{array}\right\}=-\left\{\begin{array}{l}
D_{3} \\
D_{6}
\end{array}\right\} W_{i}
$$

Where, the coefficients $D_{1}-D_{6}$ are functions of $\left(\theta_{B}\right)$ only and are given in Appendix $A$. The prediction about the direction of the $i$ th bump is as follows:

- If $P_{R i}>=T_{R i r}$ the right end of the $i$ th bump will move to the right, the transmitted force is set as $P_{R i}=T_{R i}$

- If $P_{R i}<T_{R i}$ the right end of the $i$ th bump will be pinneddown, the transmitted force is $P_{R i}=H_{R i}-\mu F_{R i}$

The vertical reaction $F_{R i}$ can be obtained using the boundary condition $\left(\delta_{V i}=0\right)$.

$$
F_{R i}=-\frac{D_{8} P_{R i}+D_{9} W_{i}}{D_{7}}
$$

Once the force at the right end of the $i$ th bump is determined, the vertex deflection of bump can be calculated using Castigliano's second theorem.

$$
\delta_{W i}=\frac{\partial U}{\partial W_{i}}=\int_{-\theta_{B}}^{0} \frac{M_{3 i}}{D L} \cdot \frac{\partial M_{3 i}}{\partial W_{i}} R_{B} d \theta+\int_{0}^{\theta_{B}} \frac{M_{4 i}}{D L} \cdot \frac{\partial M_{4 i}}{\partial W_{i}} R_{r} d \theta
$$

Substituting the moment equations into Eq. (15), yields

$$
\delta_{W i}=\frac{1}{D L}\left(D_{10} F_{R i}+D_{11} P_{R i}+D_{12} W_{i}\right)
$$

The coefficients $D_{7}-D_{12}$ are given in Appendix $A$. Then, the stiffness of the $i$ th bump foil can be defined as

$$
k_{i}^{B}=\frac{W_{i}}{\delta_{W i}}
$$

2.2 Bump foil structural linear spring model for comparing The focus of this paper is to study the dynamic performance with consideration of bump foil rounding effect in foil structure. Meanwhile, other linear spring models for bump foil in literature are also compared, which are as follows.

(1) Heshmat formula [2]

$$
K_{s}=\frac{E t^{3}}{2 s\left(1-v^{2}\right) l^{3}}
$$

(2) Iordanoff formula [10]

$$
\begin{aligned}
& K_{s}^{f w}=\frac{E t^{3} \sin ^{3}\left(\frac{\alpha}{2}\right)}{12 l^{3} s J(\mu, \alpha)\left(1-v^{2}\right)} \\
& K_{s}^{f f}=\frac{E t^{3} \sin ^{3}\left(\frac{\alpha}{2}\right)}{6 l^{3} s I(\mu, \alpha)\left(1-v^{2}\right)}
\end{aligned}
$$

Where $K_{s}^{f w}$ and $K_{s}^{f f}$ represent the stiffness for a free-free ends bump and a fixed-free end bump respectively, and $\alpha$ is the central angle of a bump arch. The specific form of parameters in Eqs. (19), (20) is shown in Appendix B.

\subsection{Prediction of dynamic and stability characteristics}

The thin air film and foil deformation are solved using FDM and FEM, respectively. The fluid motion is assumed to be laminar flow, and air is assumed as an ideal compressible gas flow. The Reynolds equation for foil bearings in the cylindrical coordinate (as shown in Fig. 1) is as

$$
-\frac{\partial}{\partial \theta}\left(\bar{p} \bar{h}^{3} \frac{\partial \bar{p}}{\partial \theta}\right)-\left(\frac{2 R}{L}\right)^{2} \frac{\partial}{\partial \bar{z}}\left(\bar{p} \bar{h}^{3} \frac{\partial \bar{p}}{\partial \bar{z}}\right)+\Lambda_{x} \frac{\partial(\bar{p} \bar{h})}{\partial \theta}+2 \gamma \Lambda_{x} \frac{\partial(\bar{p} \bar{h})}{\partial \bar{T}}=0
$$

Where, $\Lambda_{x}$ and $\gamma$ are the Reynolds number and Whirlfrequency ratios, respectively.

$$
\Lambda_{x}=\frac{6 R^{2} \omega \eta_{g}}{p_{a} c_{0}^{2}} ; \gamma=\frac{v}{\omega}
$$

The definition of dimensionless parameters is as flows:

$$
\bar{z}=\frac{z}{0.5 L} ; \bar{h}=\frac{h}{c_{0}} ; \bar{p}=\frac{p}{p_{a}} ; \bar{T}=v T
$$

Where, $L$ is the bearing length, $C_{0}$ is the radial clearance, $P_{a}$ is the environmental pressure, $\eta_{g}$ is the absolute viscosity, $v$ is the angular velocity of excitation, and $\omega$ is the angular velocity of rotation. The film thickness can be given as

$$
\bar{h}=1+\varepsilon \cos (\theta)+\frac{w_{d}}{c_{0}}
$$

Where, $\varepsilon$ is journal eccentricity, and $w_{d}$ is the deflection of the support structure.

A thick plate element model is used for the top foil (seen in Fig. 3), and the stiffness matrix [ $k]_{e}$ of plate element is of the form

$$
[k]_{e}=\left[k^{f}\right]+\left[k^{S}\right]
$$

For the isotropic case, the stiffness matrices $\left[k^{f}\right]$ and $\left[k^{s}\right]$ due to flexure and shear respectively are detailed in [19]. The stiffness matrix of top foil model $\left[k^{T}\right]$ can be obtained by adding those of plate element $[k]_{e}$ one by one. Meanwhile, the bump foil stiffness matrix $\left[k^{B}\right]$ is derived as the form of top foil stiffness matrix by considering the bump foil stiffness $k_{i}^{B}$ at the contact node between bump and top foil. The total stiffness matrix $\left[K^{G}\right]$ of the foil can be obtained by adding the top foil stiffness matrix $\left[k^{T}\right]$ and the bump foil stiffness matrix $\left[k^{B}\right]$. 


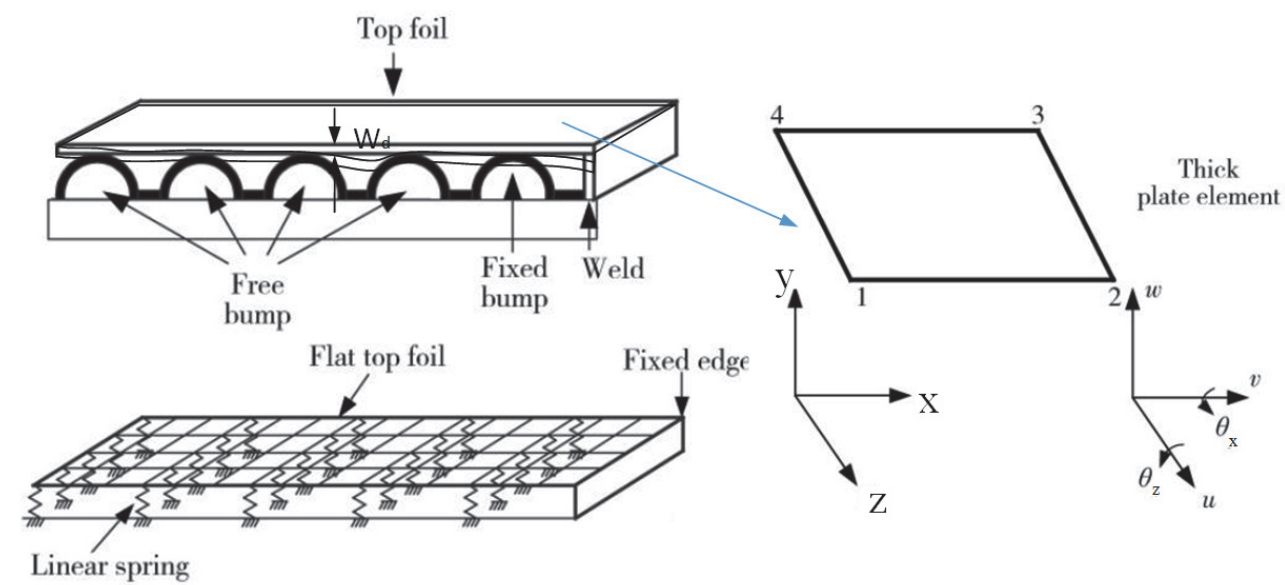

Fig. 3 Thick plate element for the top foil

$$
\left[K^{G}\right]=\left[k^{T}\right]+\left[k^{B}\right]
$$
by

The equation for deflections of the total top foil is expressed

$$
\left[K^{G}\right]\left\{U^{G}\right\}=\left\{F^{G}\right\}
$$

Where, $\left\{U^{G}\right\}$ is the displacement vector of top foil, and $\left\{F^{G}\right\}$ is the pressure vector acting on the top foil. And the expressions of $\left\{U^{G}\right\}$ and $\left\{F^{G}\right\}$ are written as follows

$$
\begin{aligned}
& \left\{U^{G}\right\}=\left\{\begin{array}{lllllll}
w_{d 1} & \theta_{z 1} & \theta_{x 1} & w_{d 2} & \theta_{z 2} & \theta_{x 2} & \ldots . . .
\end{array}\right\}^{T} \\
& \left\{F^{G}\right\}=\left\{\begin{array}{llllllll}
P_{1} & 0 & 0 & P_{2} & 0 & 0 & \ldots . . .
\end{array}\right\}^{T}
\end{aligned}
$$

where, $w_{d}$ is the vertical deflection of top foil in $y$ direction, and $\theta_{z}, \theta_{x}$ are the rotation angles about $z$ and $x$ axis, respectively. The $P_{i}$ can be got by the average film pressure of adjacent nodes. For the solution of Eq. (25), the boundary conditions at the fixed end of top foil are $\mathrm{w}=\theta_{z}=\theta_{x}=0$, and the symmetrical boundary condition at mid-plane of top foil is $\theta_{z}=0$.

The dynamic characteristics (stiffness and damping coefficients) of foil bearing are calculated by the perturbation method [19]. The journal equilibrium position $\left(x_{0}, y_{0}\right)$ is perturbed by a small displacement $(\Delta x, \Delta y)$ and a small velocity $(\Delta \dot{x}, \Delta \dot{y})$. Linearizing the force components around the steadystate equilibrium position under the assumption of small displacements of the journal, we have

$$
\left\{\begin{array}{l}
\bar{p}_{x}=\bar{p}_{x}+\bar{K}_{x x} \Delta X+\bar{K}_{x y} \Delta Y+\bar{D}_{x x} \Delta \dot{X}+\bar{D}_{x y} \Delta \dot{Y} \\
\bar{p}_{\mathrm{y}}=\bar{p}_{y}+\bar{K}_{y x} \Delta X+\bar{K}_{y y} \Delta Y+\bar{D}_{y x} \Delta \dot{X}+\bar{D}_{y y} \Delta \dot{Y}
\end{array}\right.
$$

Then the stiffness and damping coefficients are

$$
\begin{aligned}
& {\left[\begin{array}{ll}
K_{x x} & K_{x y} \\
K_{y x} & K_{y y}
\end{array}\right]=\frac{R L p_{a}}{c_{0}} \int_{-1 / 2}^{1 / 2} \int_{0}^{2 \pi}\left[\begin{array}{ll}
\bar{p}_{x} \cos \theta & \bar{p}_{y} \cos \theta \\
\bar{p}_{x} \sin \theta & \bar{p}_{y} \sin \theta
\end{array}\right] d \theta d \bar{z}} \\
& {\left[\begin{array}{ll}
D_{x x} & D_{x y} \\
D_{y x} & D_{y y}
\end{array}\right]=\frac{R L p_{a}}{c_{0} \omega} \int_{-1 / 2}^{1 / 2} \int_{0}^{2 \pi}\left[\begin{array}{ll}
\bar{p}_{x} \cos \theta & \bar{p}_{y} \cos \theta \\
\bar{p}_{x} \sin \theta & \bar{p}_{y} \sin \theta
\end{array}\right] d \theta d \bar{z}}
\end{aligned}
$$

The dimensionless stiffness and damping coefficients, $\bar{K}_{i, j}$ and $\bar{D}_{i, j}(i, j=x, y)$, are defined as

$$
\bar{K}_{i, j}=\frac{c_{0}}{0.5 P_{a} R L} K_{i, j} \quad \bar{D}_{i, j}=\frac{c_{0} \omega}{0.5 P_{a} R L} D_{i, j}
$$

To a rigid Jeffcott rotor supported horizontally by two identical journal bearings, the stability threshold speed (STS) is related to the dimensionless stiffness and damping coefficients and expressed as $\bar{\omega}_{s}$.

$$
\begin{aligned}
& K_{\text {eq }}=\left(\bar{D}_{x x} \bar{K}_{y y}+\bar{D}_{y y} \bar{K}_{x x}-\bar{D}_{x y} \bar{K}_{y x}-\bar{D}_{y x} \bar{K}_{x y}\right) /\left(\bar{D}_{x x}+\bar{D}_{y y}\right) \\
& \gamma_{s}^{2}=\left(\left(K_{e q}-\bar{K}_{x x}\right)\left(K_{e q}-\bar{K}_{y y}\right)-\bar{K}_{y x} \bar{K}_{x y}\right) /\left(\bar{D}_{x x} \bar{D}_{y y}-\bar{D}_{x y} \bar{D}_{y x}\right) \\
& \bar{\omega}_{s}=\sqrt{K_{e q} / \gamma_{s}^{2}}
\end{aligned}
$$

Where $K_{e q}$ and $\gamma_{s}$ are the equivalent stiffness and approximate whirl-frequency ratios, respectively. For most fluid film journal bearing, the stiffness and damping coefficients have the following approximate relationship as

$$
\bar{K}_{x x} \approx \bar{K}_{y y}, \bar{K}_{x y}+\bar{K}_{y x} \approx 0, \bar{D}_{x x} \approx \bar{D}_{y y}, \bar{D}_{x y} \approx \bar{D}_{y x}, \bar{D}_{x y} \ll \bar{D}_{x x}
$$

By substituting Eq. (35) into Eqs. (32)-(34), a simplified threshold speed is obtained as

$$
K_{e q}=\bar{K}_{x x}, \gamma_{s}^{2}=\left(\bar{K}_{x y} / \bar{D}_{x x}\right)^{2}, \quad \bar{\omega}_{s}^{*}=\bar{D}_{x x} \sqrt{\bar{K}_{x x}}|| \bar{K}_{x y} \mid
$$

Equation (36) succinctly indicates the relationship between the STS and the dynamic coefficients. The increase of direct stiffness and damping coefficients can raise the STS, but the latter has a lager effect. Meanwhile, the STS is inversely proportional to the cross-coupling stiffness coefficients. The dynamic coefficients and STS are finally obtained from Eqs. (28)(34).

\subsection{Experiment design}

As shown in Fig. 4 , three bump foil bearings with $R_{r}=$ $0,1 \mathrm{~mm}$, and $2 \mathrm{~mm}$ are designed and manufactured. Due to the error of manufacturing and stamping process, the actual rounding radius is $0.2 \mathrm{~mm}, 1.19 \mathrm{~mm}$ and $2.23 \mathrm{~mm}$ respectively. The static stiffness test platform is shown in Fig. 4. The shaft is inserted into the radial foil bearing, and deformation is generated by force exerted on the bump foil under heavy load. The stiffness characteristics of the bump foil can be obtained through the force-displacement curve. To verify the stiffness model proposed in this paper, loading tests are carried out along different angles of the bearing.

To verify the accuracy of the above theoretical stability analysis, a motorized centrifugal compressor with two foil bearings was built up. Its configuration was specially designed so that the journal bearing can be replaced and tested under completely same operation condition (Fig. 5). Two vibration transducers are horizontally fixed by magnetic holders at the front and rear bearing positions to monitor the bearing vibration. Since the vibration of the radial position can well 


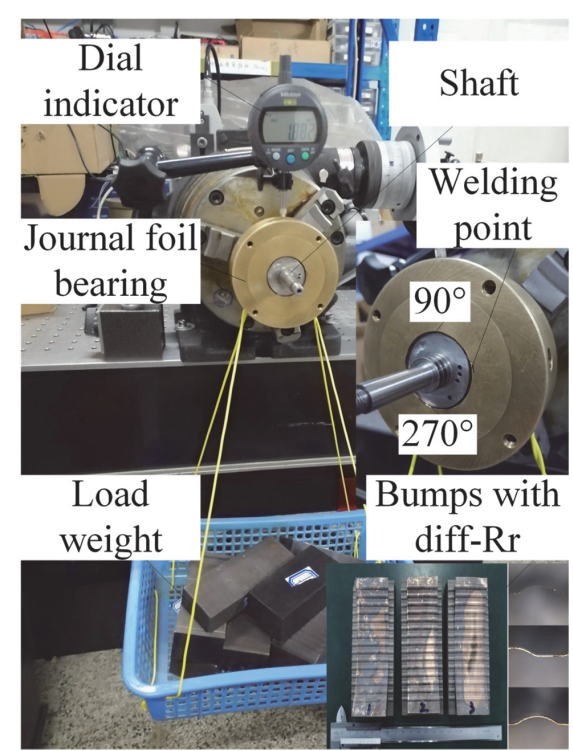

Fig. 4 Experimental setup of structural stiffness for foil bearing with various rounding radius
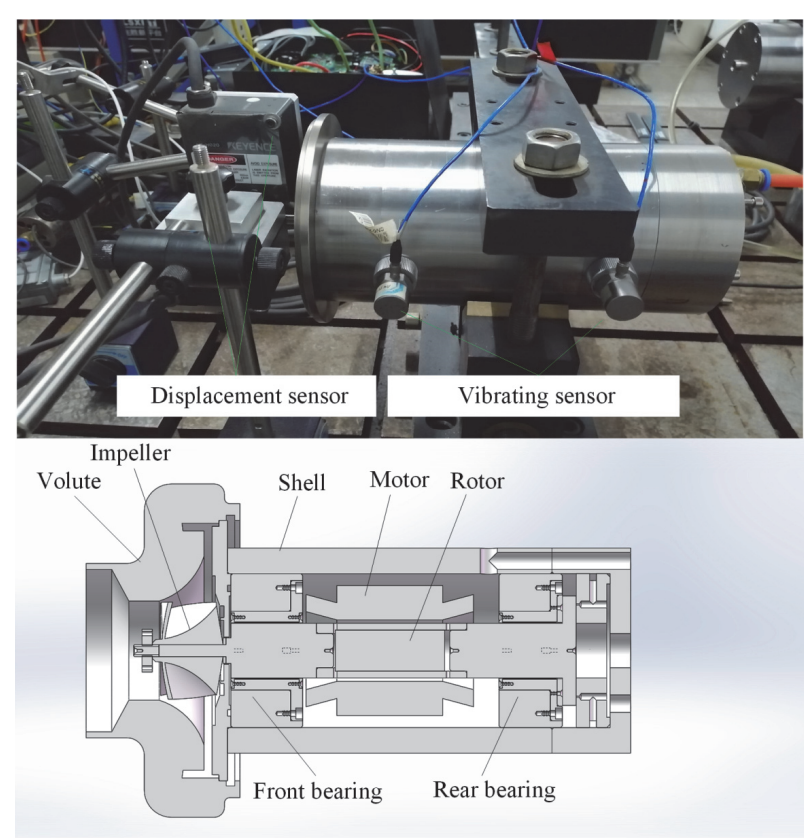

Fig. 5 Test compressor for the dynamic performance of foil bearings

reflect the dynamic performance of bearing stiffness and damping effect, a drive controller is adopted to make the speed of the compressor from 0 up to $80000 \mathrm{r} / \mathrm{min}$, and two acceleration sensor is used on the bearing position of shell to measure vibration during this process. Finally, the vibration waterfall figure is obtained for foil bearing with different rounding radius.

\section{Results and discussion}

3.1 Model verification and Bump foil stiffness characteristics

In order to assess the validity of the present model, the predicted results of bump foil deflection are compared to previous models. The geometrical parameters of the present model are selected to the same as the literature (Le Lez et al. [5], Feng and Kaneko [6], Hryniewicz et al. [7], and Abdelrasoul [8]) and are given in Table 1. Figure 6(a) shows the deflection of bumps using the present model and the previous literature models for $R_{r}=0$ under uniform load. As shown, the results are almost identical. Figure 6(b) presents the bump stiffness for different rounding radius under increasing-decreasing load. The bump with the same stiffness is in the fixed region, and the bump with varying stiffness is in the slip region. It can be seen that the rounding radius has a great effect on the stiffness of bumps, especially in the fixed region. That is because the introduction of the rounding changes the contact and friction area between the bump foil and the bearing sleeve, which leads to a shorter connection plate between adjacent bumps, and affects the stress on the bump arch and the heritability among bumps.

Figure 6(c) displays the bump foil stiffness for different friction coefficients, which is with the rounding radius $0.5 \mathrm{~mm}$ and under the increasing-decreasing load. The bump stiffness is almost the same in the fixed region. However, when the friction coefficients are higher, the number of the fixed bump foil increases, which means an increased structural stiffness. It can be seen that the stiffness of bumps in the fixed area is significantly higher, compared to the bumps in the slipping region. For a certain number of bumps in a journal foil bearing, more fixed bumps and less slipping bumps means total structural stiffness is enhanced. So the larger the number of the fixed bump is, the greater the stiffness of the bump is. However, it should note that the slipping between bump foil and top foil as well as bump foil and bearing sleeve is very important to the friction damping providing resistance to shock vibration. Specially, the bump stiffness calculated by Heshamt formula [3] is far smaller than the present prediction in the fixed area, as it does not consider the friction force in the analysis. Figure 6(d) shows that with the increase of the rounding radius, the average stiffness of bump foil first increases and then decreases, and

Table 1 Geometrical parameters and material specifications of bearing

\begin{tabular}{cc}
\hline Parameter & Values \\
\hline Radius of bump foil $R_{B}(\mathrm{~mm})$ & 3.3636 \\
Bearing length $L(\mathrm{~mm})$ & 38.1 \\
Bearing radius $R(\mathrm{~mm})$ & 19.05 \\
Foil thickness $t(\mathrm{~mm})$ & 0.102 \\
Bump height $h$ B $(\mathrm{mm})$ & 0.508 \\
Bump half length $l(\mathrm{~mm})$ & 1.91 \\
Bump pitch $s(\mathrm{~mm})$ & 4.572 \\
Rounding radius $R \mathrm{r}(\mathrm{mm})$ & $0.5-2.0$ \\
Number of bumps $N$ & 26 \\
Young's modulus $E(\mathrm{GPa})$ & 214 \\
Poisson's ratio $v$ & 0.29 \\
Friction coefficient $\mu$ & $0-0.3$ \\
Friction coefficient $\eta$ & $0-0.3$ \\
Nominal clearance $c 0(\mathrm{~mm})$ & 0.0318 \\
Gas motion viscosity $\eta_{\mathrm{g}}(\mathrm{Pa} \cdot \mathrm{s})$ & $1.932 \mathrm{e}-05$ \\
\hline
\end{tabular}



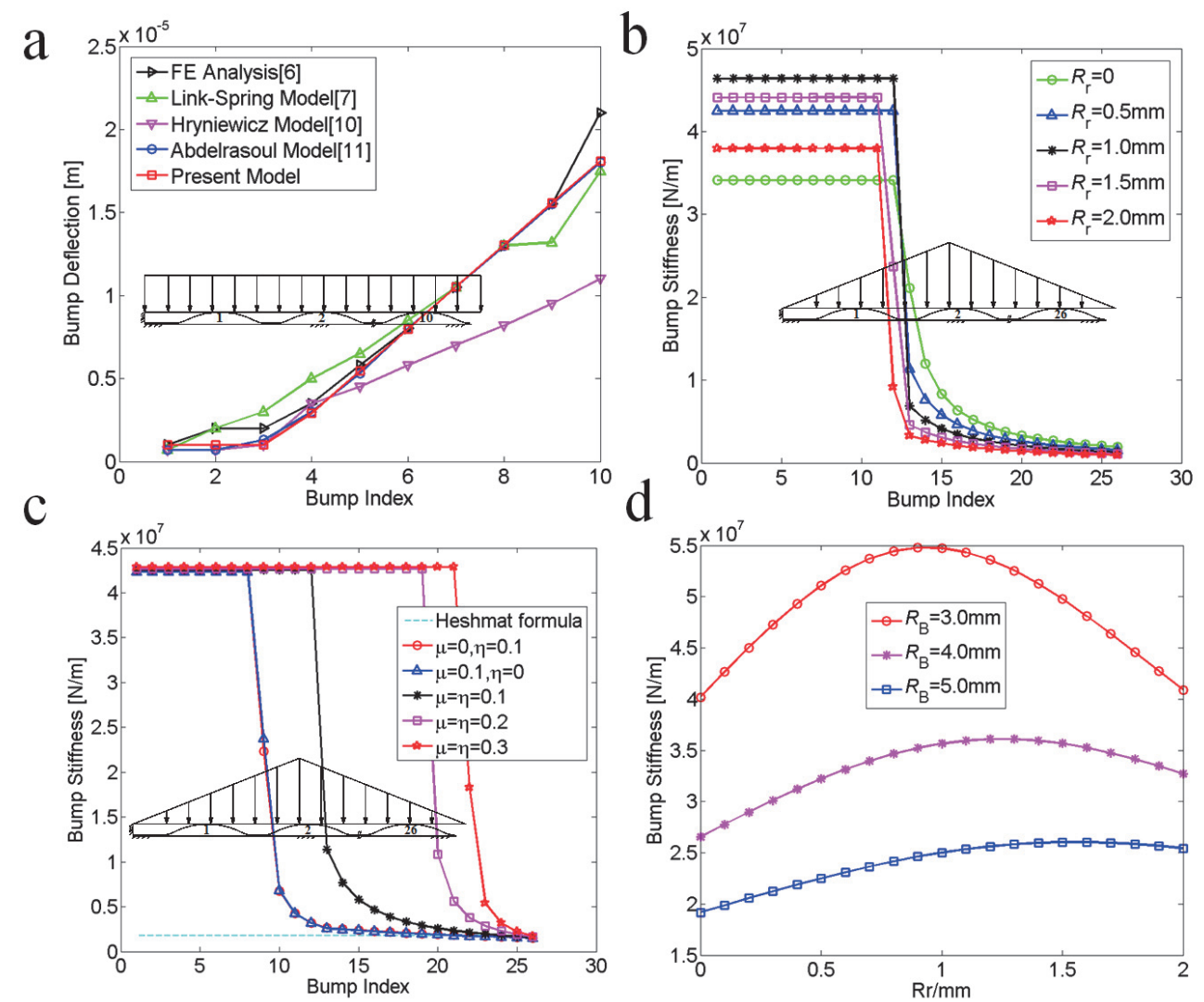

Fig. 6 Predicted bump characteristics for various conditions: (a) deflections for uniform lord, (b) stiffness for rounding radius, (c) stiffness for friction coefficients, (d) stiffness for bump radius

there is an optimal rounding radius $R_{r}$ for determined bump radius $R_{B}$ to maximum the stiffness. The above discussions suggest that the rounding and friction has a certain effect on the bump stiffness. With the different combination of rounding radius and friction coefficients, we can get a needed structural stiffness for the air foil bearing.

\subsection{Dynamic characteristics}

Figures 7(a)-(d) displays predicted gas foil bearing stiffness coefficients versus excitation frequency for different bump foil structural models. A static load of $16.7 \mathrm{~N}$ is applied at 30,000 $\mathrm{rpm}$, and the eccentricity ratio of the journal center at the equilibrium position is about 0.4 . The excitation frequency is from 50 to $1500 \mathrm{~Hz}$ for the dynamic analysis. As shown, when the excitation frequency is greater than the subsynchronous excitation frequency $250 \mathrm{~Hz}$, the direct stiffness coefficients $\left(K_{\mathrm{x} x}\right.$ $K_{y y}$ ) increase with excitation frequency. The stiffness coefficients of gas foil bearing for Heshmat formula and Iordanoff formula are almost the same because they have a similar foil structural stiffness characteristic. However, since the structural stiffness for the present analysis is much greater than linear spring models (seen in Fig. 6(c)), the predicted stiffness coefficients of are greater under the same excitation frequency. The direct and cross-coupled stiffness is also greater when there is an increasing friction coefficient and a suitable rounding radius.

Figures $8(a)-(d)$ shows the predicted damping coefficients versus excitation frequency for different bump foil models under the same condition as that in Fig. 7. It can be seen that the damping coefficients of foil bearing with Heshmat formula and Iordanoff formula are almost the same, and are much smaller than the presented prediction. The predicted direct damping coefficients with larger friction coefficients and a suitable rounding radius $\left(R_{r}=1 \mathrm{~mm}\right)$ is higher. However, the cross-coupled damping coefficients are less affected by the friction and rounding and go to zero as the increase of excitation frequency. Also, as the increase of excitation frequency, the difference among results of each model becomes smaller. As shown, it has a greater influence on the damping coefficients when the disturbance ratio is less than 1 (the excitation frequency is less than $500 \mathrm{~Hz}$ ), and the law presents certain complexity. It is worth noting that the direct damping coefficient of foil bearing at each excitation frequency is positive and the cross-coupled damping at large excitation frequency is very small, which is conducive to providing energy dissipation for the vibration of the bearing-rotor system, thus improving stability.

Figure 9 shows the dimensionless stiffness and damping coefficients versus rounding radius when the friction coefficient $u=\eta=0.1$. It can be seen that with the increase of rounding radius, the direct stiffness coefficient $K_{\mathrm{xx}}, K_{\mathrm{yy}}$ and damping coefficient $D_{\mathrm{xx}}, D_{\mathrm{yy}}$ tend to reduce after the first rise, the crosscoupled stiffness $K_{\mathrm{xy}}, K_{\mathrm{yx}}$ firstly decreases and then present rising trend. However, the radius has a negligible effect on the damping coefficient $D_{\mathrm{xy}}$ and $D_{\mathrm{yx}}$. So, there exists an optimum rounding radius to maximize the direct stiffness and damping coefficients, which has a great significance for improving the stability.

\subsection{Stability analysis}

Figure 10 depicts the dimensionless STS under different model and conditions. As shown in Fig. 10(a), compared with Heshmat and Iordanoff formula, the STS for the present model 

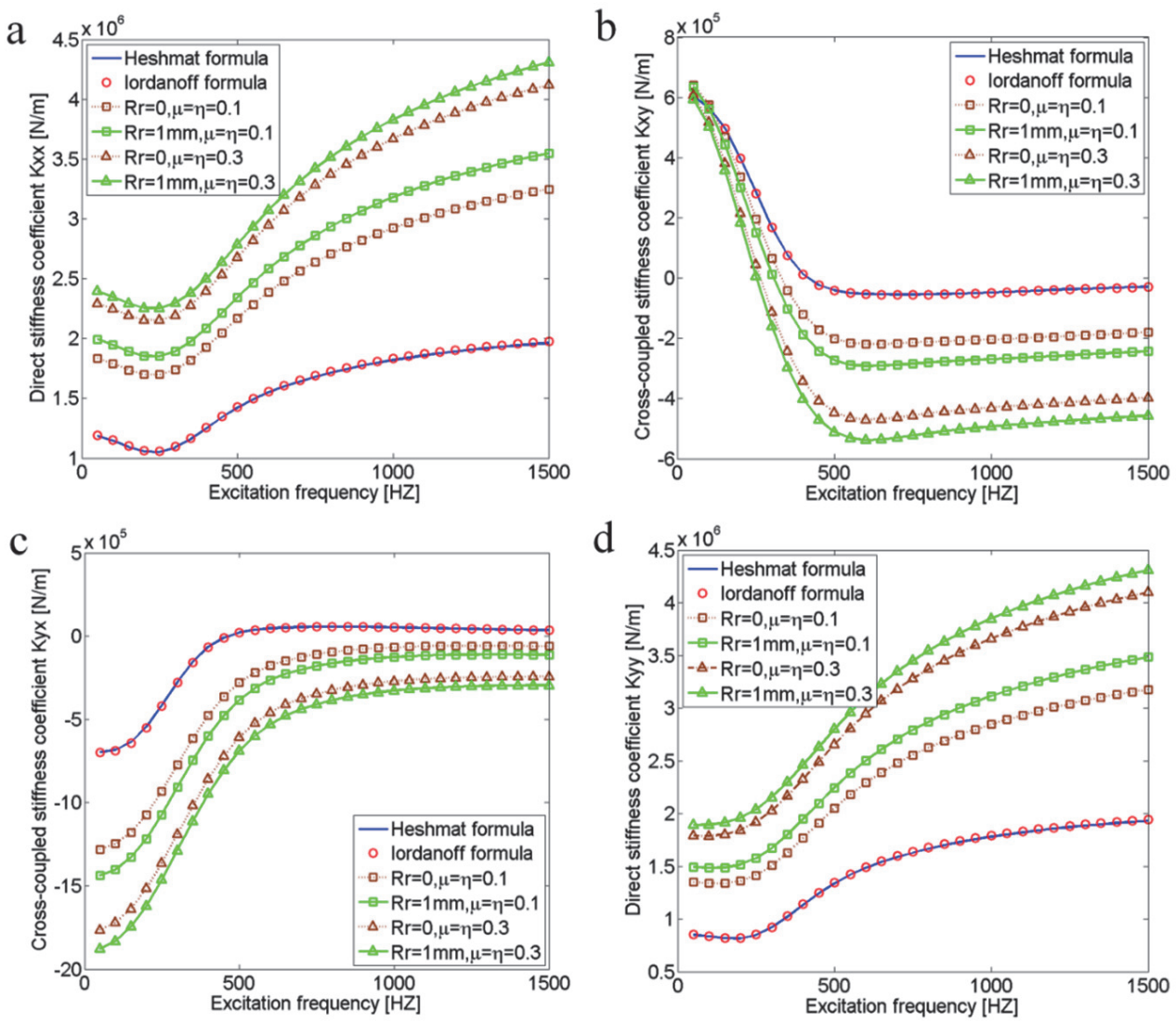

Fig. 7 Predicted gas foil bearing stiffness coefficients versus excitation frequency for different bump foil structural models. Rotor speed: $30 \mathrm{krpm}$, Static load: $80 \mathrm{~N}$
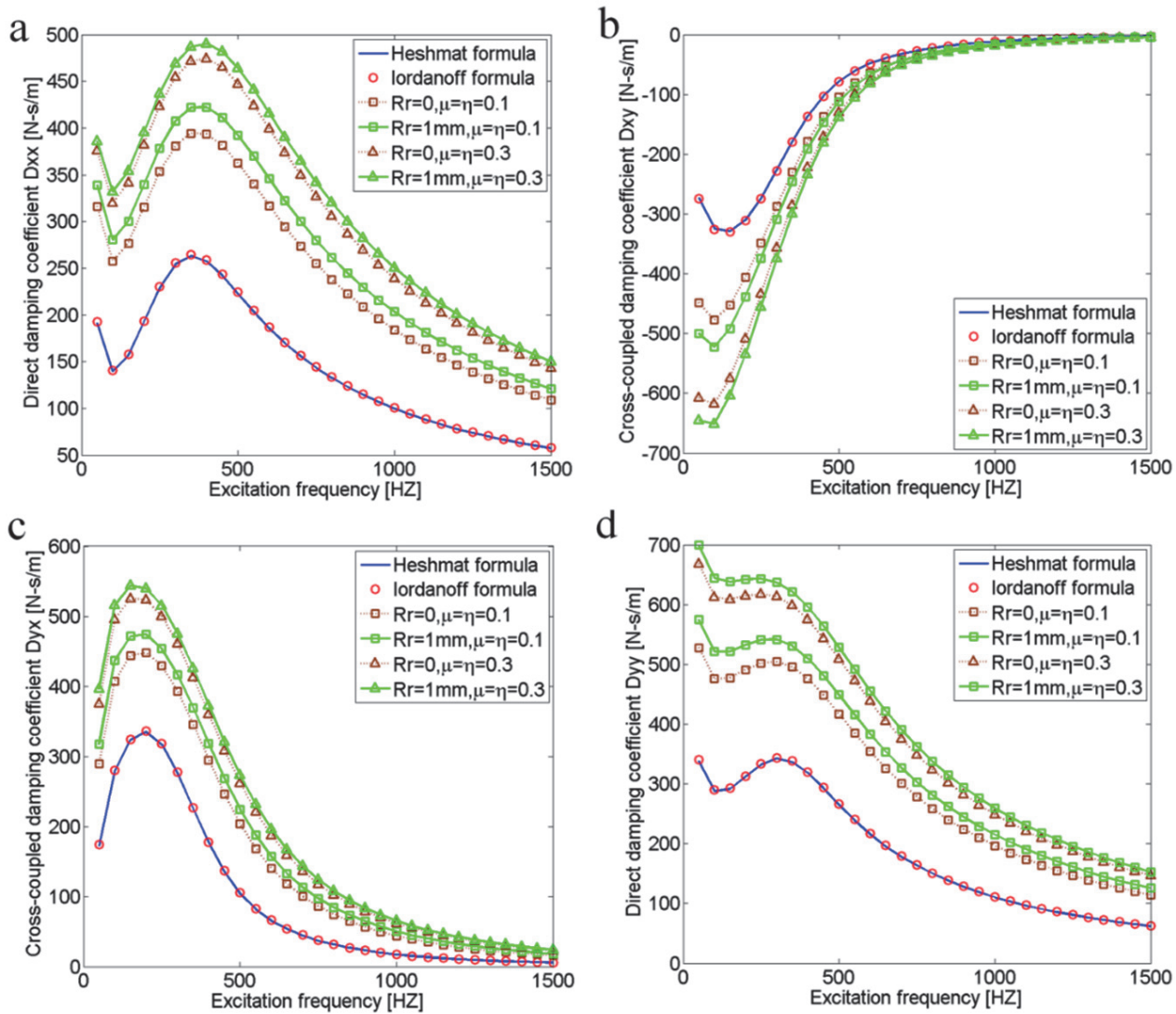

Fig. 8 Predicted gas foil bearing damping coefficients versus excitation frequency for different bump foil structural models. Rotor speed: $30 \mathrm{krpm}$, Static load: $80 \mathrm{~N}$ 


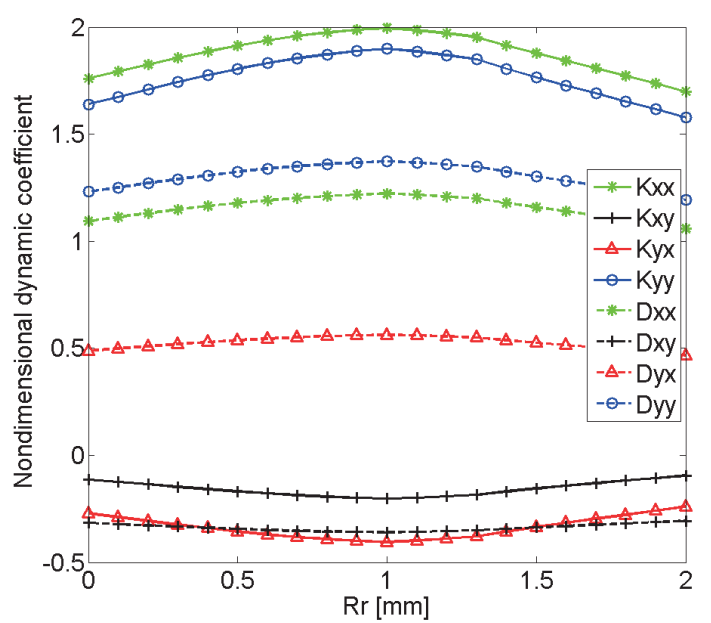

Fig. 9 Predicted dimensionless STS for different models
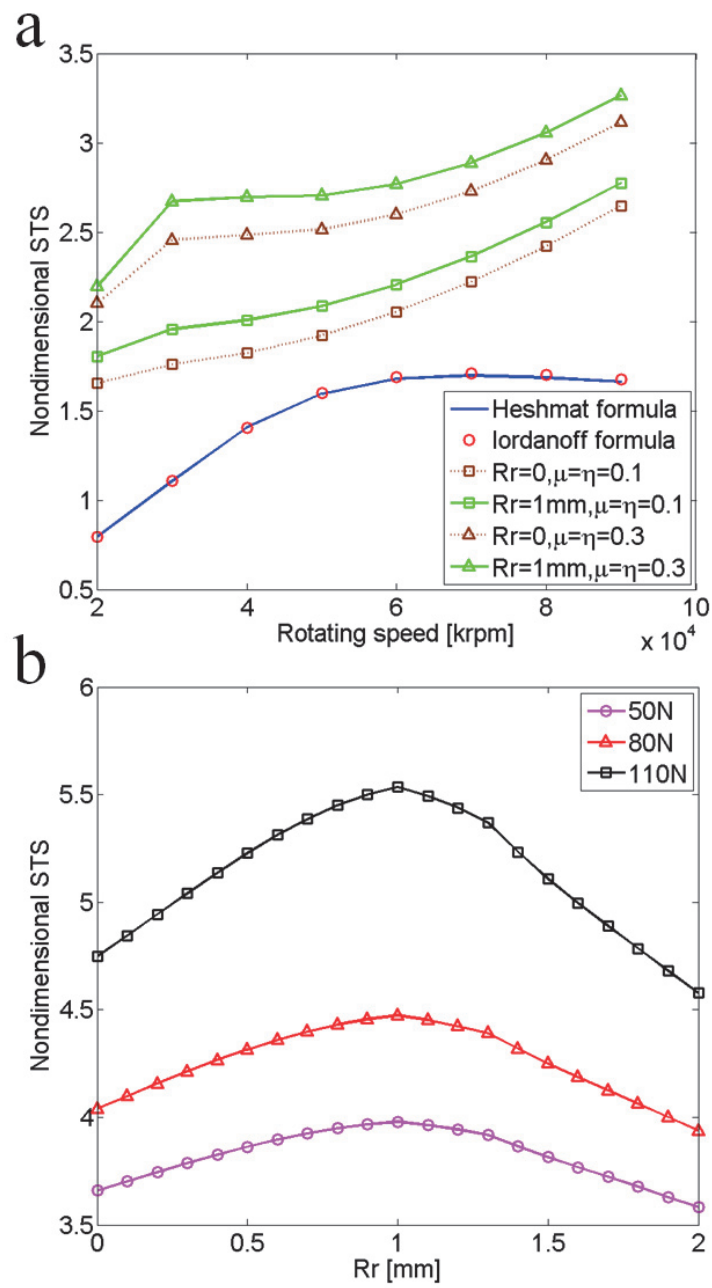

Fig. 10 Predicted dimensionless STS for different conditions: (a) versus rotating speed, (b) versus rounding radius

considering friction and rounding is much higher. We can see that the STS can be improved by increasing the friction coefficients between top foil and bump foil, as well as between bump foil and bearing housing. The STS is also higher when there is a suitable rounding radius $\left(R_{r}=1 \mathrm{~mm}\right)$.

For further study in the effect of rounding radius on the stability, the dimensionless STS of the bearing-rotor system with rounding under different static loads is shown in Fig. 10(b). It can be seen that the static load acting on the bump foil of gas bearing has a great influence on the STS, and the greater the static load is, the more obvious the influence is. With the increase of the rounding radius, the STS first increases and then decreases, which shows great consistency with the variation of direct dynamic coefficients. There is an optimal rounding radius (in this case, $R_{B}=3.336 \mathrm{~mm}, R_{r}=1 \mathrm{~mm}$ ) to maximize the STS, which well verifies the conclusion drawn in Fig. 9. As a summary, the results suggest that increasing the structural stiffness has a beneficial effect on stability for foil journal bearings, which is consistent with the study result conducted by Schiffmann [20]. However, it is noted that a foil bearing with zero compliance defeats the purpose and is not to be compared as a rigid cylindrical bearing is introduced.

\subsection{Experimental verification}

The bearing force-displacement test curve is shown in Fig. 11. It can be seen that under the same loading force, the displacement of bearing without rounding is maximum, and that of $R_{r}=1 \mathrm{~mm}$ is minimum. The correctness of the theoretical conclusion that there is an optimal rounding radius to maximize the structural stiffness of foil bearings is further verified. Due to the friction between top foil and bump foil, as well as between bump foil and bearing sleeve, the deformation curve of unloading is obviously lower than that of loading, and there is an obvious hysteresis phenomenon, which indicates the importance of considering friction in the modeling of bump stiffness. At the same time, it can be seen from the results that the stiffness becomes greater with the increase of load, showing a strong nonlinear feature, which should be considered in the next study on the bump stiffness.

Figures 12 (a) and (b) shows the experimental waterfalls of the foil bearings with the $R_{r}=0$ and $R_{r}=1$, respectively. Without the rounding, the maximum amplitude of fundamental frequency vibration is $0.87 \mathrm{~g}$. However, when there is an optimal rounding radius, the maximum amplitude is reduced to a value of $0.51 \mathrm{~g}$. Meanwhile, a decrease appears for the doublefrequency with the rounding radius $R_{r}=1 \mathrm{~mm}$, which can be obviously observed up to the speed of $60 \mathrm{krpm}$. Some obvious high-frequency vibrations is also disappeared. Under the same

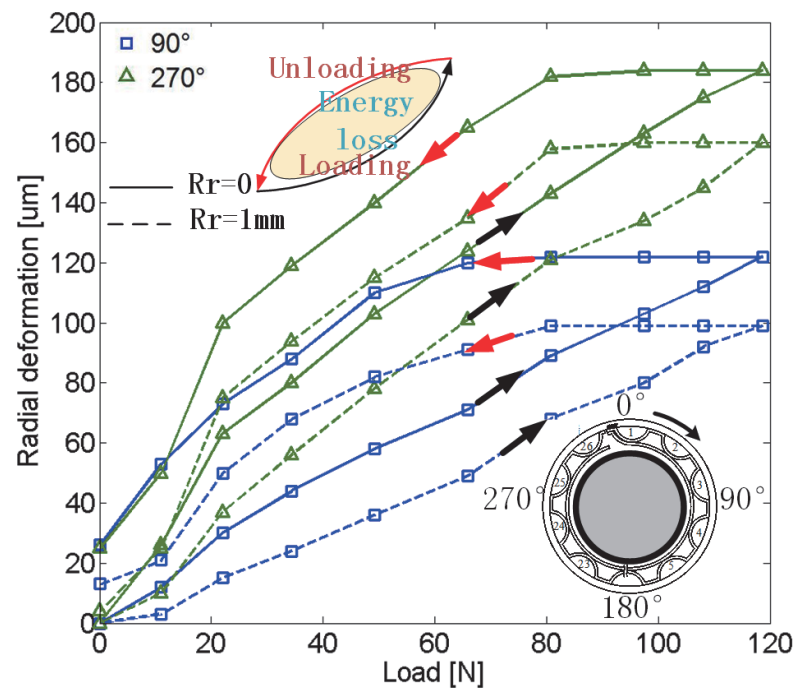

Fig. 11 Variation of displacement versus load 


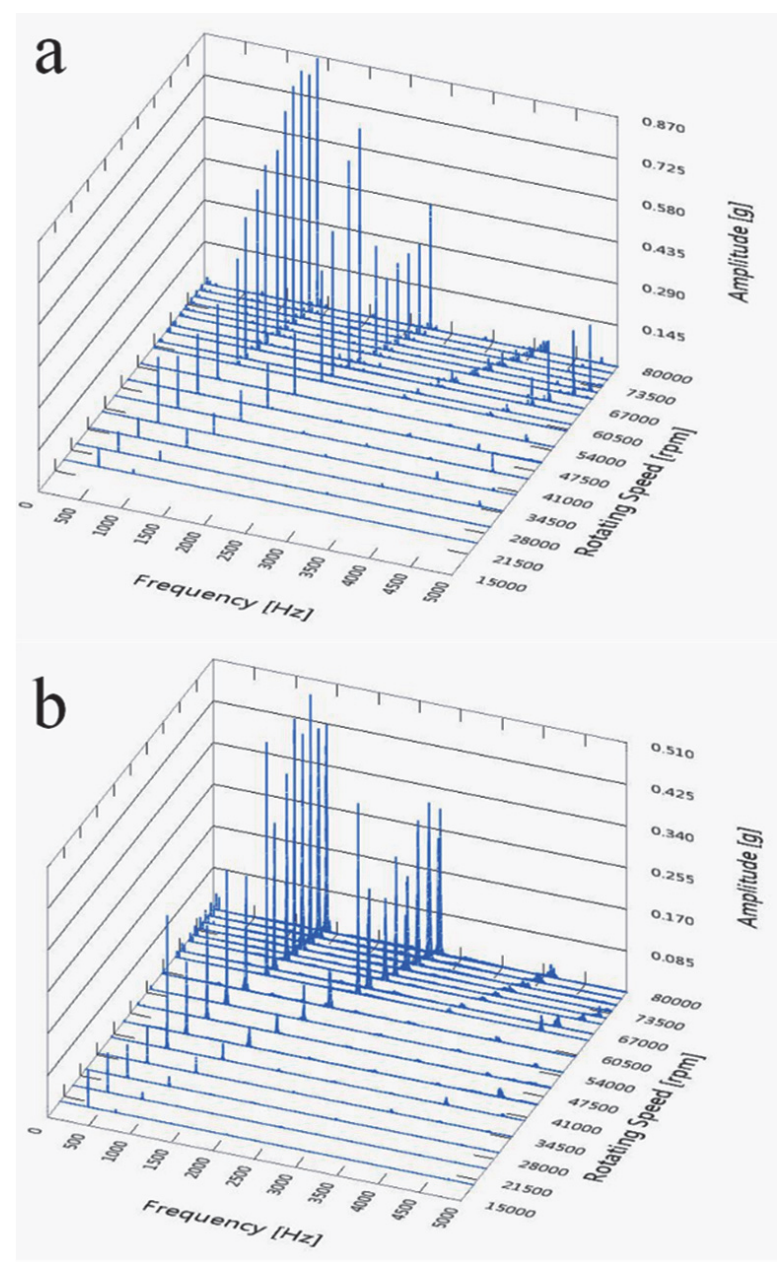

Fig. 12 Waterfalls of the two bearings: (a) $R_{r}=0$, (b) $R_{r}=1 \mathrm{~mm}$

running condition, the rotor supported by traditional foil bearing is more easy to reach the stability threshold speed. All this characteristics are beneficial to the improvement of bearingrotor dynamic performance, which also means an increased STS. This indicates that the foil bearing with an optimal rounding radius is more stable within the whole experimental speed range, which is in good agreement with the theoretical stability analysis.

\section{Conclusions}

This study presented a structural stiffness model of bump foil considering the rounding between the bump foil and the bridge. The model account for the bearing geometry, friction, and interaction between bumps in the bump foil and the comparison with previous analytical data and experiments showed the validity of the proposed model. The dynamic characteristics of foil bearing was calculated by the perturbation method, and the effect of the rounding radius on the stiffness, damping, and stability characteristics of bearings were investigated systematically in this paper. The remarkable conclusions from this study can be summarized as follows.

- As the rounding radius increases, the stiffness of the bump foil firstly increases and then decreases. There is an optimal rounding radius that makes the bump stiffness maximum. The friction force between the bump foil and top foil as well as between the bump foil and bearing housing can increase the stiffness of bump foil.

- The direct stiffness and damping coefficients and the magnitude of the cross-coupled stiffness coefficient are higher when there is an increasing friction coefficient and a suitable rounding radius. However, the cross-coupled damping coefficients are less affected by friction and rounding.

- The STS of model having a suitable rounding radius and higher friction usually is higher under different lords, which means the rounding and friction force can increase the stability of bearing-rotor system, which can mainly be attributed to the increased structural stiffness of foil bearings.

\section{Acknowledgement}

The authors wish to thank the China Ministry of Industry and Information Technology and the Industrial Foundation Engineering for financially supporting this research.

\section{References}

[1] Walowit, J. A. and Anno, J. N., "Modern Development of Lubrication Mechanics," Applied Science Publishers, London, 1975, 105.

[2] Heshmat, H., Walowit, J. A. and Pinkus, O., "Analysis of GasLubricated Foil Journal Bearings," J. Tribol., 105, 4, 1983, 647-655.

[3] Ku, C. P. and Heshmat, H., “Compliant Foil Bearing Structural Stiffness Analysis: Part I-Theoretical Model Including Strip and Variable Bump Foil Geometry," J. Tribol., 114, 2, 1992, 394-400.

[4] Carpino, M. and Talmage, G., "A Fully Coupled Finite Element Formulation for Elastically Supported Foil Journal Bearings," STLE Tribol. Trans., 46, 4, 2003, 560-565.

[5] Lez, S. L., Arghir, M. and Frene, J., "Static and Dynamic Characterization of a Bump-Type Foil Bearing Structure," J. Tribol., 129, 1, 2007, 75-83.

[6] Feng, K. and Kaneko, S., "Analytical Model of Bump-Type Foil Bearings Using a Link-Spring Structure and a Finite-Element Shell Model," J. Tribol., 132, 2, 2010, 021706.

[7] Hryniewicz, P., Wodtke, M., Olszewski, A. and Rzadkowski, R., "Structural Properties of Foil Bearings: A Closed-Form Solution Validated with Finite Element Analysis," STLE Tribol. Trans., 52, 4, 2009, 435-446.

[8] Gad, A. M. and Kaneko, S., "A New Structural Stiffness Model for Bump-Type Foil Bearings: Application to Generation II Gas Lubricated Foil Thrust Bearing," J. Tribol., 136, 4, 2014, 041701.

[9] Swanson, E. E., "Bump Foil Damping Using a Simplified Model," J. Tribol., 128, 3, 2006, 542-550.

[10] Peng, J. P. and Carpino, M., “Coulomb Friction Damping Effects in Elastically Supported Gas Foil Bearings," STLE Tribol. Trans., 37, 1, 1994, 91-98.

[11] Lehn, A., Mahner, M. and Schweizer, B., “Elasto-Gasdynamic Modeling of Air Foil Thrust Bearings with a Two-Dimensional Shell Model for Top and Bump Foil," Tribol. Int., 100, 2016, 48-59.

[12] San Andreś, L. and Kim, T. H., "Improvements to the Analysis of Gas Foil Bearings: Integration of Top Foil 1D and 2D Structural Models," ASME Turbo Expo 2007: Power for Land, Sea, and Air, GT2007-27249, 2007, 779-789.

[13] Xu, F., Liu, Z., Zhang, G. and Cao, Z., "Effects of Shear Stiffness in Top Foil Structure on Gas Foil Bearing Performance Based on Thick Plate Theory," Proceedings of the Institution of Mechanical Engineers, Part J: Journal of Engineering Tribology, 227, 7, 2013, 761776. 
[14] Xu, F., Zhang, G., Sun, Y., Liu, Z., Wang, Y. and Xu, N., "The Effect of Coulomb Friction in Foil Structure on the Static and Dynamic Performance of Bump Foil Journal Bearings," ASME Turbo Expo 2014: Turbine Technical Conference and Exposition, Dusseldorf, GT2014-25038, 2014, 16-20.

[15] Hryniewicz, P., Wodtke, M., Olszewski, A. and Rzadkowski, R., "Structural Properties of Foil Bearings: A Closed-Form Solution Validated with Finite Element Analysis," STLE Tribol. Trans., 52, 4, 2009, 435-446.

[16] Boresi, A. P. and Schmidt, R. J., "Advanced Mechanics of Materials, 6th Edition," John Wiley \& Sons, New York, 2002.

[17] Timoshenko, S. and Goodier, J. N., "Theory of Elasticity, 2nd Edition," McGraw-Hill, New York, 1951.

[18] Beer, F. P., Johnston, E. R., DeWolf, J. T. and Mazurek, D. F., “Mechanics of Materials, 6th Edition," McGraw-Hill, New York, 2008.

[19] Petyt, M., "Introduction to Finite Element Vibration Analysis, 2nd Edition," Cambridge University Press, New York, 2010.

[20] Schiffmann, J. and Spakovszky, Z. S., "Foil Bearing Design Guidelines for Improved Stability," Proc. 24th Conference on Mechanical Vibration and Noise, Chicago, 2012.

\section{Appendix $A$}

$$
\begin{aligned}
& D_{1}=R_{B}^{3} I_{1}+R_{B}^{2} R_{r} I_{2}+R_{B} R_{r}^{2} I_{3}+R_{r}^{3} I_{4} \\
& D_{2}=R_{B}^{3} I_{5}+R_{B}^{2} R_{r} I_{6}+R_{B} R_{r}^{2} I_{7}+R_{r}^{3} I_{8} \\
& D_{3}=R_{B}^{3}\left(I_{9}+\eta I_{13}\right)+R_{B}^{2} R_{r}\left(I_{10}+\eta I_{14}\right)+R_{B} R_{r}^{2}\left(I_{11}+\eta I_{14}\right)+R_{r}^{3}\left(I_{12}+\eta I_{13}\right) \\
& D_{4}=R_{B}^{3} I_{15}+R_{B}^{2} R_{r} I_{16}+R_{B} R_{r}^{2} I_{17}+R_{r}^{3} I_{18} \\
& D_{5}=D_{1} \\
& D_{6}=R_{B}^{3}\left(I_{19}+\eta I_{23}\right)+R_{B}^{2} R_{r}\left(I_{20}+\eta I_{24}\right)+R_{B} R_{r}^{2}\left(I_{21}+\eta I_{25}\right)+R_{r}^{3}\left(I_{22}+\eta I_{26}\right) \\
& D_{7}=R_{B}^{3}\left(I_{15}+\mu I_{1}\right)+R_{B}^{2} R_{r}\left(I_{16}+\mu I_{2}\right)+R_{B} R_{r}^{2}\left(I_{17}+\mu I_{3}\right)+R_{r}^{3}\left(I_{18}+\mu I_{4}\right) \\
& D_{8}=D_{1} \\
& D_{9}=D_{6} \\
& D_{10}=R_{B}^{3}\left(I_{19}+\mu I_{9}\right)+R_{B}^{2} R_{r}\left(I_{20}+\mu I_{10}\right)+R_{B} R_{r}^{2}\left(I_{21}+\mu I_{11}\right)+R_{r}^{3}\left(I_{22}+\mu I_{12}\right) \\
& D_{11}=R_{B}^{3} I_{9}+R_{B}^{2} R_{r} I_{10}+R_{B} R_{r}^{2} I_{11}+R_{r}^{3} I_{12} \\
& D_{12}=R_{B}^{3}\left(I_{27}-\eta I_{9}\right)+R_{B}^{2} R_{r}\left[I_{28}-\eta\left(\frac{I_{24}-I_{11}}{2}\right)\right]+R_{B} R_{r}^{2}\left[I_{29}-\eta\left(\frac{I_{25}-I_{10}}{2}\right)\right] \\
& +R_{r}^{3}\left[I_{30}-\eta\left(\frac{I_{26}-I_{9}}{2}\right)\right]
\end{aligned}
$$

Where, $I_{1} \sim I_{30}$ is just the function of $\theta_{\mathrm{B}}$.

$I_{1}=-2 \sin ^{2} \theta_{B}+\theta_{B} \sin 2 \theta_{B}$

$I_{2}=-2 \sin ^{2} \theta_{B}-2 \theta_{B} \sin \theta_{B}+2 \theta_{B} \sin 2 \theta_{B}$

$I_{3}=2 \sin ^{2} \theta_{B}-4 \theta_{B} \sin \theta_{B}+\theta_{B} \sin 2 \theta_{B}$

$I_{4}=2 \sin ^{2} \theta_{B}-2 \theta_{B} \sin \theta_{B}$

$I_{5}=\theta_{B}-\frac{3}{2} \sin 2 \theta_{B}+2 \theta_{B} \cos ^{2} \theta_{B}$

$$
\begin{aligned}
& I_{6}=4 \sin \theta_{B}-2 \sin 2 \theta_{B}-4 \theta_{B} \cos \theta_{B}+4 \theta_{B} \cos ^{2} \theta_{B} \\
& I_{7}=2 \theta_{B}+2 \theta_{B} \cos ^{2} \theta_{B}-4 \theta_{B} \cos \theta_{B} \\
& I_{8}=3 \theta_{B}-4 \sin \theta_{B}+\frac{1}{2} \sin 2 \theta_{B} \\
& I_{9}=1-\frac{1}{2} \sin ^{2} \theta_{B}-\cos \theta_{B} \\
& I_{10}=1-2 \cos \theta_{B}+\cos ^{2} \theta_{B} \\
& I_{11}=-\sin ^{2} \theta_{B}+\theta_{B} \sin \theta_{B} \\
& I_{12}=-1+\cos \theta_{B}+\theta_{B} \sin \theta_{B}-\frac{1}{2} \sin ^{2} \theta_{B} \\
& I_{13}=\frac{1}{2} \theta_{B}-\frac{1}{4} \sin 2 \theta_{B}-\sin \theta_{B}+\theta_{B} \cos \theta_{B} \\
& I_{14}=-\theta_{B}+\sin \theta_{B}-\frac{1}{2} \sin 2 \theta_{B}+\theta_{B} \cos \theta_{B} \\
& I_{15}=\theta_{B}-\frac{1}{2} \sin 2 \theta_{B}+2 \theta_{B} \sin ^{2} \theta_{B} \\
& I_{16}=8 \theta_{B} \sin ^{2} \theta_{B} \\
& I_{17}=-4 \sin \theta_{B}+2 \sin 2 \theta_{B}+10 \theta_{B} \sin ^{2} \theta_{B} \\
& I_{18}=\theta_{B}-4 \sin \theta_{B}+\frac{3}{2} \sin 2 \theta_{B}+4 \theta_{B} \sin ^{2} \theta_{B} \\
& I_{19}=-\frac{1}{2} \theta_{B}+\frac{3}{4} \sin 2 \theta_{B}-\sin \theta_{B} \\
& I_{20}=-\sin \theta_{B}+\frac{1}{2} \sin 2 \theta_{B}-2 \theta_{B} \sin ^{2} \theta_{B} \\
& I_{21}=3 \sin \theta_{B}-\frac{3}{2} \sin 2 \theta_{B}-4 \theta_{B} \sin ^{2} \theta_{B} \\
& I_{22}=-\frac{1}{2} \theta_{B}+3 \sin \theta_{B}-\frac{5}{4} \sin 2 \theta_{B}-2 \theta_{B} \sin ^{2} \theta_{B} \\
& I_{23}=1-\cos \theta_{B}-\frac{3}{2} \sin ^{2} \theta_{B}+\theta_{B} \sin \theta_{B} \\
& I_{24}=-\sin ^{2} \theta_{B}+3 \theta_{B} \sin \theta_{B}-\theta_{B} \sin 2 \theta_{B} \\
& I_{25}=-2+2 \cos \theta_{B}+3 \sin ^{2} \theta_{B}+2 \theta_{B} \sin \theta_{B}-2 \theta_{B} \sin 2 \theta_{B} \\
& I_{26}=-1+\frac{5}{2} \sin ^{2} \theta_{B}-\theta_{B} \sin 2 \theta_{B}+\cos \theta_{B} \\
& I_{27}=\frac{1}{2} \theta_{B}-\frac{1}{4} \sin 2 \theta_{B} \\
& I_{28}=\theta_{B} \sin ^{2} \theta_{B} \\
& I_{29}=-2 \sin \theta_{B}+\sin 2 \theta_{B}+2 \theta_{B} \sin ^{2} \theta_{B}
\end{aligned}
$$


$I_{30}=\frac{1}{2} \theta_{B}-2 \sin \theta_{B}+\frac{3}{4} \sin 2 \theta_{B}+\theta_{B} \sin ^{2} \theta_{B}$

\section{Appendix $B$}

$$
\begin{aligned}
& J(u, \alpha)=y_{a}\left[\left(\cos \frac{\alpha}{2}-1\right)\left(\sin \frac{\alpha}{2}+u \cos \frac{\alpha}{2}\right)+\frac{u(1-\cos \alpha)}{4}\right] \\
& +\left(1-y_{a}\right)\left(\frac{\alpha}{4}-\frac{\sin \alpha}{4}\right) \\
& y_{a}=\frac{-\left(\frac{3 \cdot \sin \alpha}{4}-\frac{\alpha}{4}-\sin \frac{\alpha}{2}\right)}{\alpha \sin \frac{\alpha}{2}\left(\sin \frac{\alpha}{2}+u \cos \frac{\alpha}{2}\right)-2 u \sin ^{2}\left(\frac{\alpha}{2}\right)+\frac{\alpha}{2}-\sin \frac{\alpha}{2}} \\
& I(u, \alpha)=\left(A^{2}+\frac{1+u^{2}}{2}\right) \frac{\alpha}{2}-\frac{\left(1-u^{2}\right) \sin \alpha}{4}-\frac{u(\cos \alpha-1)}{2} \\
& \quad-2 A\left(1-\cos \frac{\alpha}{2}+u \sin \frac{\alpha}{2}\right) \\
& A=\sin \frac{\alpha}{2}+u \cos \frac{\alpha}{2}
\end{aligned}
$$

\section{Nomenclature}

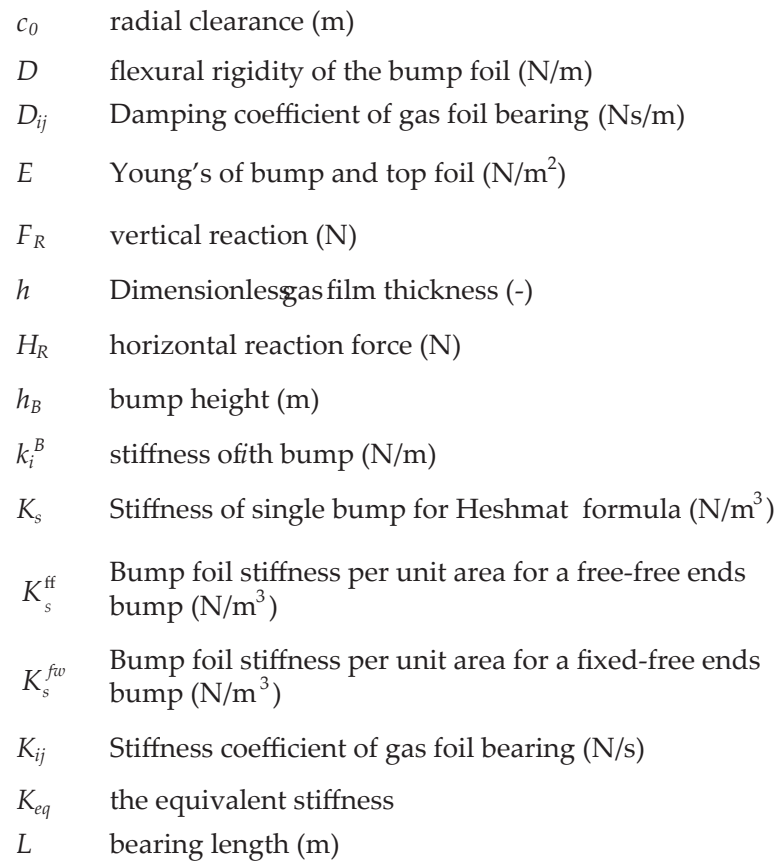

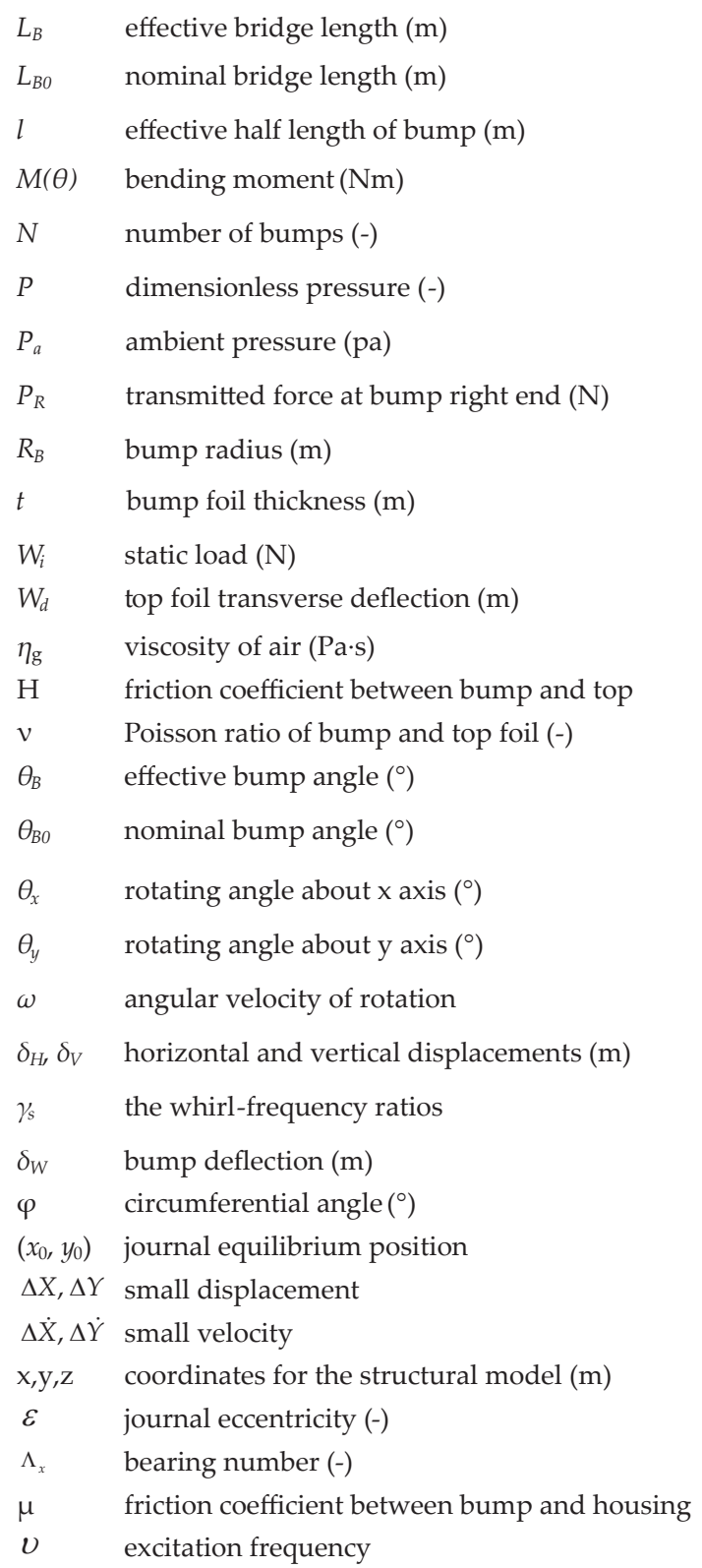

\section{Vectors and matrices}

$\left\{F^{G}\right\} \quad$ vector of presures acting on the top foil

$\left\{U^{\sigma}\right\} \quad$ vector of displacement for foil structure

$\left[k^{B}\right] \quad$ global stiffness matrix of bump foil

$\left[K^{\text {G }} \quad\right.$ global stiffness of total model 